\title{
RESEARCH PAPER RP913
}

Part of Journal of Research of the National Bureau of Standards, Volume 17, September 1936

\section{COMPARISON OF DATA ON THE IONOSPHERE, SUNSPOTS, AND TERRESTRIAL MAGNETISM*}

\author{
By Elbert B. Judson
}

\section{ABSTRACT}

Ionosphere data of the National Bureau of Standards from 1930 to 1935 are compared with data on the earth's magnetic field intensity and sunspot numbers. Seasonal variations of $\mathrm{F}_{2}$ critical frequency and virtual height are compared with sunspot numbers and magnetic activity. Correlation of annual averages of the ionosphere critical frequencies with sunspot numbers is shown. Variations of midnight $\mathrm{F}_{2}$ critical frequencies are compared with variations of sunspot numbers and magnetic activity.

It has been shown ${ }^{1}$ that there are relations between variations in radio field intensities and similar variations in sunspot activity and disturbances in the earth's magnetic field. The dependence of longdistance radio transmission upon the ionosphere is well known, and it is, therefore, of interest to examine the possible relations between ionosphere data and data on sunspot activity and terrestrial magnetism. It is the purpose of this paper to compare ionosphere data obtained at the National Bureau of Standards from 1930 to 1935 with sunspot activity and variations of the earth's magnetic field during the same period.

The theory and method of measurement of ionosphere phenomena have been treated elsewhere. ${ }^{23}$ There are three principal regions of the ionosphere capable of returning radio waves back to the earth; the $\mathrm{E}$ region, about 100 to $120 \mathrm{~km}$ in virtual height, the $\mathrm{F}_{1}$ region, about 200 to $230 \mathrm{~km}$ in virtual height, and the $\mathrm{F}_{2}$ region, about 240 to $500 \mathrm{~km}$ in virtual height, depending upon the season and time of day. The presence of the $\mathrm{F}_{1}$ region is most marked during the summer day. At night the $\mathrm{F}_{1}$ and $\mathrm{F}_{2}$ regions combine to form the night $\mathrm{F}$ region, as shown in figure 1.

Two important kinds of data are available for each region from ionosphere measurements, namely, the critical frequency or penetration frequency ${ }^{4}$ and the virtual height of the region. From the critical frequency the ionization density is calculated.

\footnotetext{
*A preliminary version of this paper was presented at the Institute of Radio Engineers Convention in Detroit, Mich., July 3,1935 .

1 G. W. Pickard, Correlation of radio reception with solar activity and terrestrial magnetism. Proc. Inst. Radio Engrs. 15, 83-97 (February 1927); 15, 749-766 (September 1927). C. N. Anderson, Notes on the effect of solar disturbances on transatlantic radio transmission. Proc. Inst. Radio Engrs. 17, 1528-1535 (September 1929). L. W. Austin, Comparison between sunspot numbers, intensity of the earth's magnetic field, and strength of radiotelegraphic signals. J. Wash. Acad. Sci. 20, 73-74 (1930), and others.

2 Pedersen, Propagation of Radio Waves. Chapters V and VI, Copenhagen.

3 S. S. Kirby, L. V. Berkner, and D. M. Stuart. Studies of the ionosphere and their application to radio transmission. BS J. Research 12, 13 (1934) RP632; Proc. Inst. Radio Engrs. 22, 4 (April 1934). Also references contained therein.

4 The critical or penetration frequency is defined as the lowest radio frequency of a wave which penetrates the region at normal incidence. The critical frequency of the ordinary ray of the $\mathrm{F}_{1}$ region is referred to as $f^{0} \mathrm{~F}_{1}$. The critical frequency of the ordinary ray of the $\mathrm{F}_{2}$ is known as $f^{0} \mathrm{~F}_{2}$ and for the extraordinary ray, $f^{\times}{ }_{\mathrm{F} 2}$. There is a separation of approximately $800 \mathrm{kc} / \mathrm{s}$ between the critical frequency of the ordinary and extraordinary rays in the $\mathrm{F}$ regions. The critical frequency of the $\mathrm{E}$ region is given as $f_{\mathrm{E}}$.
} 
The critical frequency of each region has a definite diurnal characteristic variation. The $\mathrm{E}$ critical frequency increases rapidly near sunrise and later more slowly to a maximum at noon, decreasing

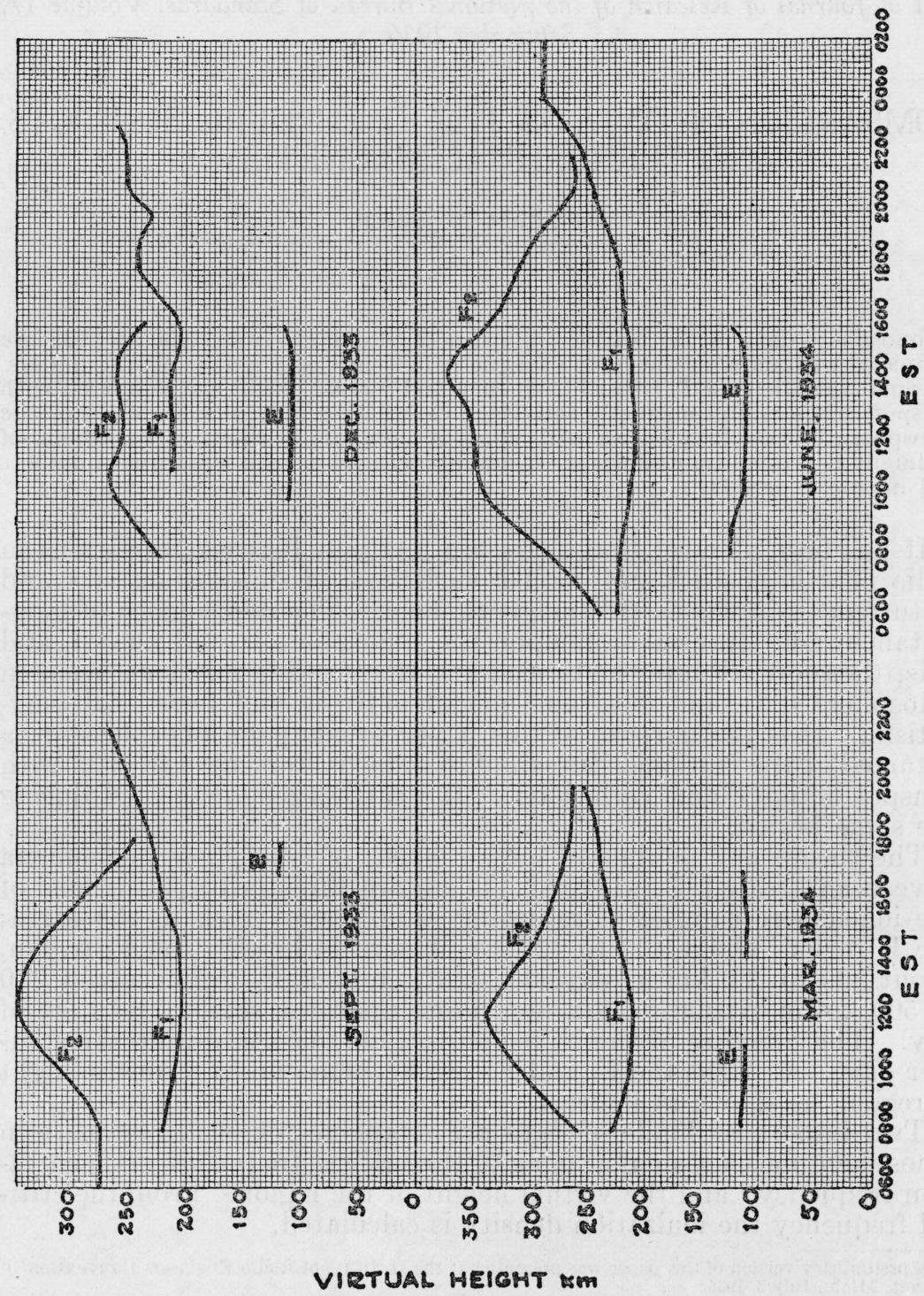

FIGURE 1.-Average diurnal variation of virtual height of the three ionosphere; regions for four seasons.

slowly"during the afternoon and rapidly near sunset. The $\mathrm{F}_{1}$ region does not form until several hours after sunrise and then $f_{F_{1}}$ increases slowly to a maximum near noon, decreasing slowly during the afternoon until the $\mathrm{F}_{1}$ region disappears several hours before sunset. The diurnal curves for $f_{\mathrm{E}}$ and $f^{0} \mathrm{~F}_{1}$ are given in detail by Gilliland. ${ }^{5}$ The

Theodore R. Gilliland, Multifrequency ionosphere recording and its significance. J. Research NBS 14, 283-303 (1935) RP769; Proc. Inst. Radio Engrs. 23, 1076-1101 (September 1935). 
$\mathrm{F}_{2}$ critical frequency varies more irregularly than those of the $\mathrm{E}$ or $\mathrm{F}_{1}$ regions. During the winter $f_{\mathrm{F}_{2}}$ is highest just after noon and lowest just before sunrise, while during the summer it is highest just about sunset.

Since there is greater variation in the critical frequency and virtual height of the $\mathrm{F}_{2}$ region than of the other regions, and since there are data available for this region over a longer period of time, this paper deals mainly with the $\mathrm{F}_{2}$ region.

Noon critical frequency and virtual height measurements have been made manually once each week in the vicinity of Washington, D. C., since early in 1930. Since May 1933, automatic multifrequency records have been made hourly in the frequency band 2,500 to 4,400 $\mathrm{kc} / \mathrm{s}$. Although more complete and accurate data are available for 1933 to 1935 , the earlier data give indications of some value.

Figure 2 shows weekly noon values of the $\mathrm{F}_{2}$ critical frequency extraordinary ray during 1934 and 1935, compared with the sunspot numbers and the magnetic character of the days. The sunspot numbers are the Zürich provisional numbers, while the magnetic character number for each day is that reported by the Cheltenham Magnetic Observatory of the U. S. Coast and Geodetic Survey. The noon (1200 EST) values are not necessarily the maximum points of the diurnal curves. They were selected because the majority of observations during 1930, 1931, and 1932 were taken at or near noon. Here the curve for the year 1934 is placed directly above that of 1935 for comparison. The dotted portion of each curve indicates periods when no data were available. The blank spaces in the critical-frequency curves represent times when no reflections from the $\mathrm{F}_{2}$ region were returned, or when the $\mathrm{F}_{2}$ region was masked by a sporadic E layer. ${ }^{6}$

It will be noticed that the critical-frequency values for 1935 were generally higher than for the corresponding time in 1934. Sunspot numbers and magnetic activity were greater in 1935 than in 1934. An examination of the individual days in both years showed no consistent agreement between the curves for the critical frequency and those for the cosmic data. A decrease in critical frequency seemed as likely to happen on quiet days as on magnetically active days. The low values of critical frequency during the summers of 1934 and 1935 and the high values during the winters are indicative of the regular seasonal variation.

Weekly values of noon $\mathrm{F}_{2}$ critical frequency (extraordinary ray $f^{x}{ }_{F 2}$ ) and the virtual height of the $F_{2}$ region (for Washington, D. C.) were averaged by months for Sept. 1930 to Dec. 1935, inclusive, and are plotted in figure 3 . The $\mathrm{F}_{2}$ virtual heights plotted were those observed between 4,000 and 5,000 kc/s. The monthly averages of sunspot numbers and the variation of the horizontal component of the earth's magnetic field are also shown in figure 3.

An examination of the critical-frequency and virtual-height curves shows the marked seasonal variation repeating each year and usually having high daytime critical frequencies around February and November of each year. Much lower values of critical frequency are obtained during the summer months. It is of interest to note that when the $f^{x}$ is high the virtual height is low, and vice versa. This condition has also been found to hold for individual days.

- Samuel S. Kirby and Elbert B. Judson. Recent studies of the ionosphere. J. Research NBS 14, 469-486 (1935) RP780; Proc. Inst. Radio Engrs. 23, 733-751 (July 1935). 
The graph of the variation in the horizontal component of the earth's magnetic field is placed directly below that of virtual height and critical frequency to show the similarity in the seasonal variations.
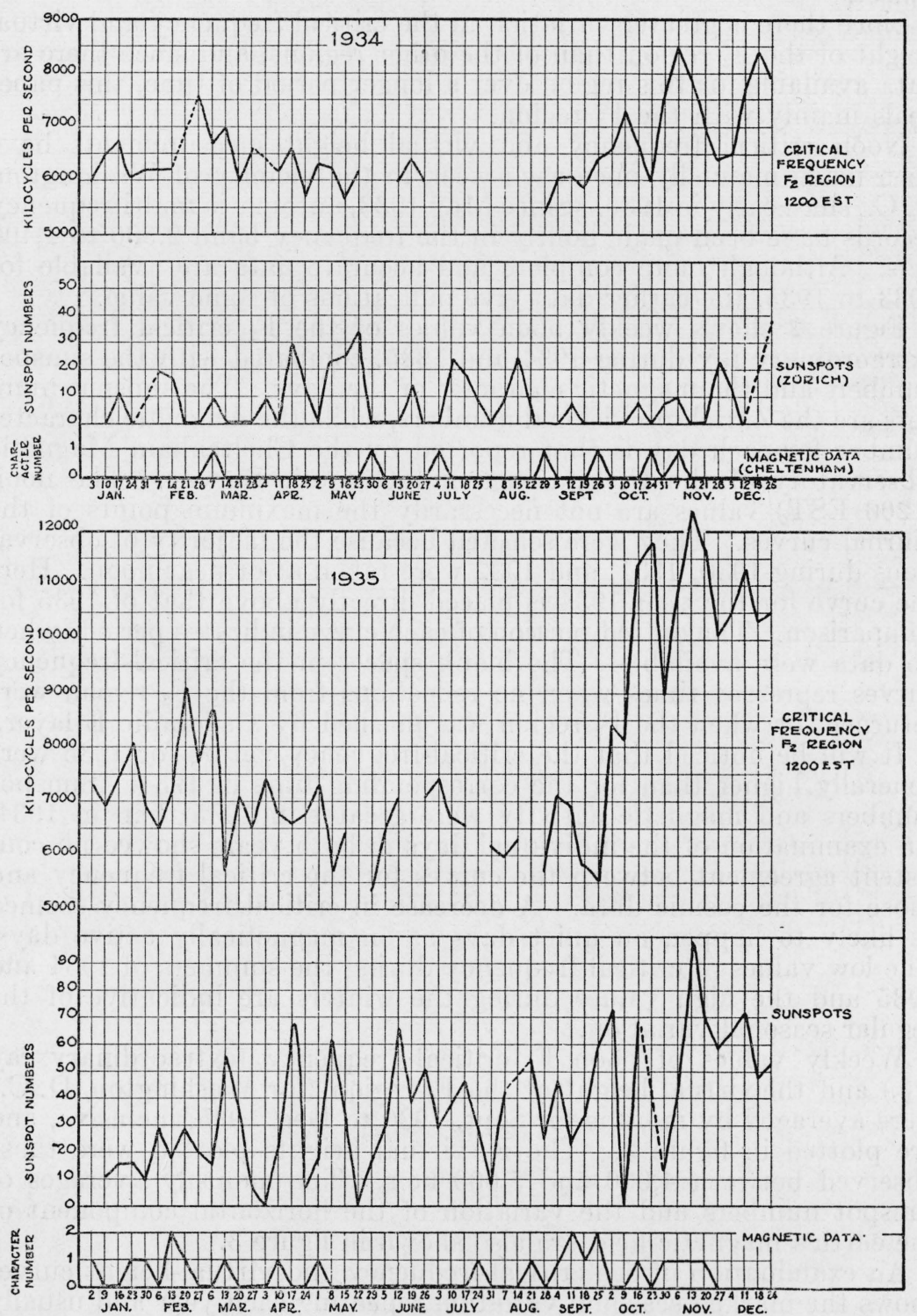

FIGURE 2.-Comparison of 1934 and 1935 weekly noon $\mathrm{F}_{2}$ critical frequencies with sunspot numbers and magnetic activity.

The seasonal curve of virtual heights follows fairly well the seasonal curve of magnetic disturbances. The critical-frequency curve and the curve for the magnetic variations appear to have an inverse relationship. From these comparisons it could not however be concluded that low critical frequencies regularly occur during short 
periods of pronounced magnetic activity. A comparison of the critical-frequency curve with the average sunspot curve shows no certain correlation between the two phenomena for corresponding months. There is, however, a similar general trend when considering the envelopes of the two curves.
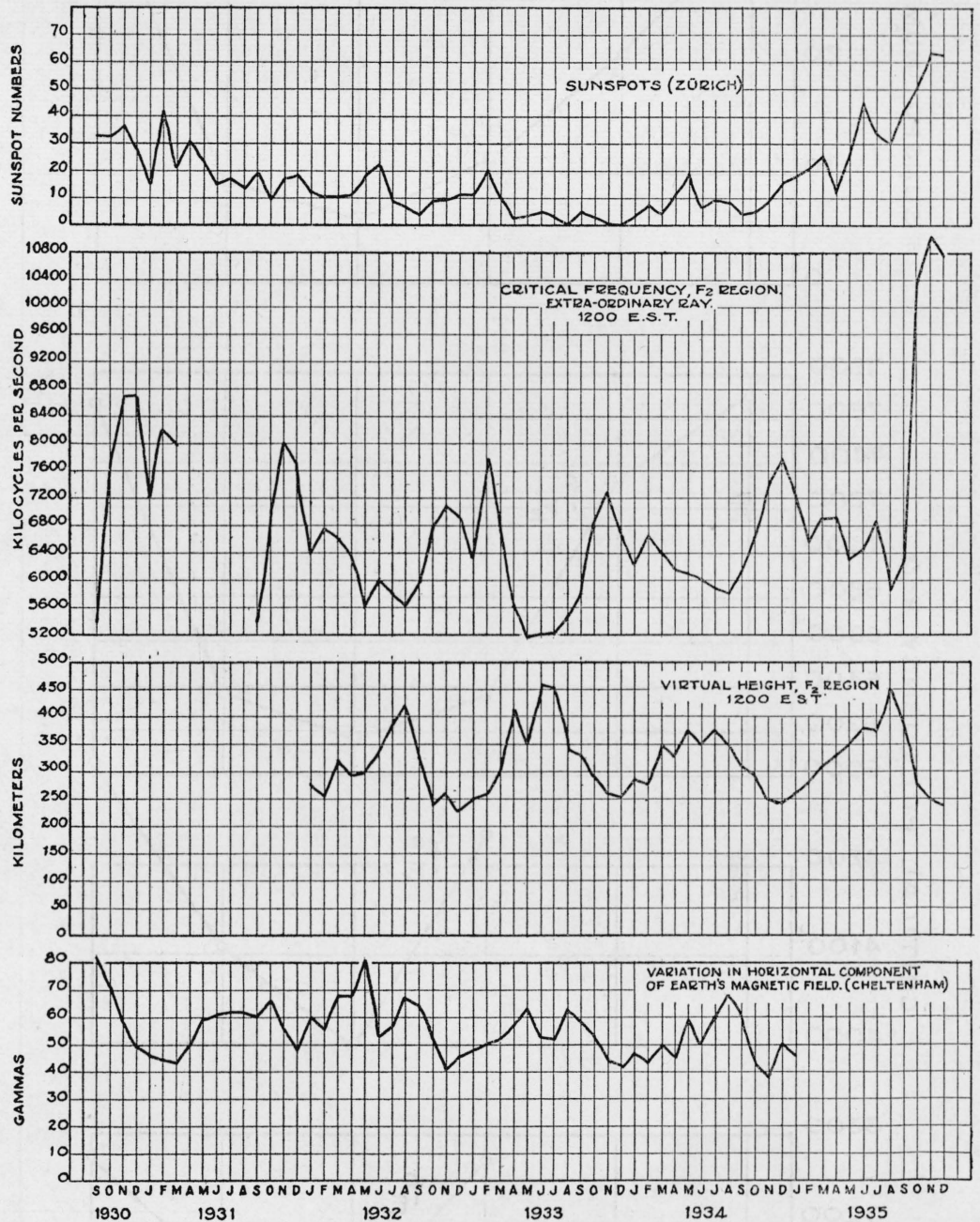

FIgURE 3.-Seasonal and annual variation of monthly averages of $F_{2}$ critical frequency, $F_{2}$ virtual height, sunspot numbers, and magnetic activity.

Annual averages of critical frequencies and sunspots were next considered. In figure 4 the annual averages of sunspot numbers, the critical frequency, extraordinary ray, of the $\mathrm{F}_{2}$ region, ordinary ray, of the $F_{1}$ region and the critical frequency of the $E$ region, are plotted for comparison. The sunspot numbers and $\mathrm{F}_{2}$ critical-frequency curves are closely related, reaching a minimum in 1933, and rising rapidly together from 1934 to 1935 . The $F_{1}$ and $\mathrm{E}$ region critical frequencies seem to vary similarly, but the trend is much less pro- 

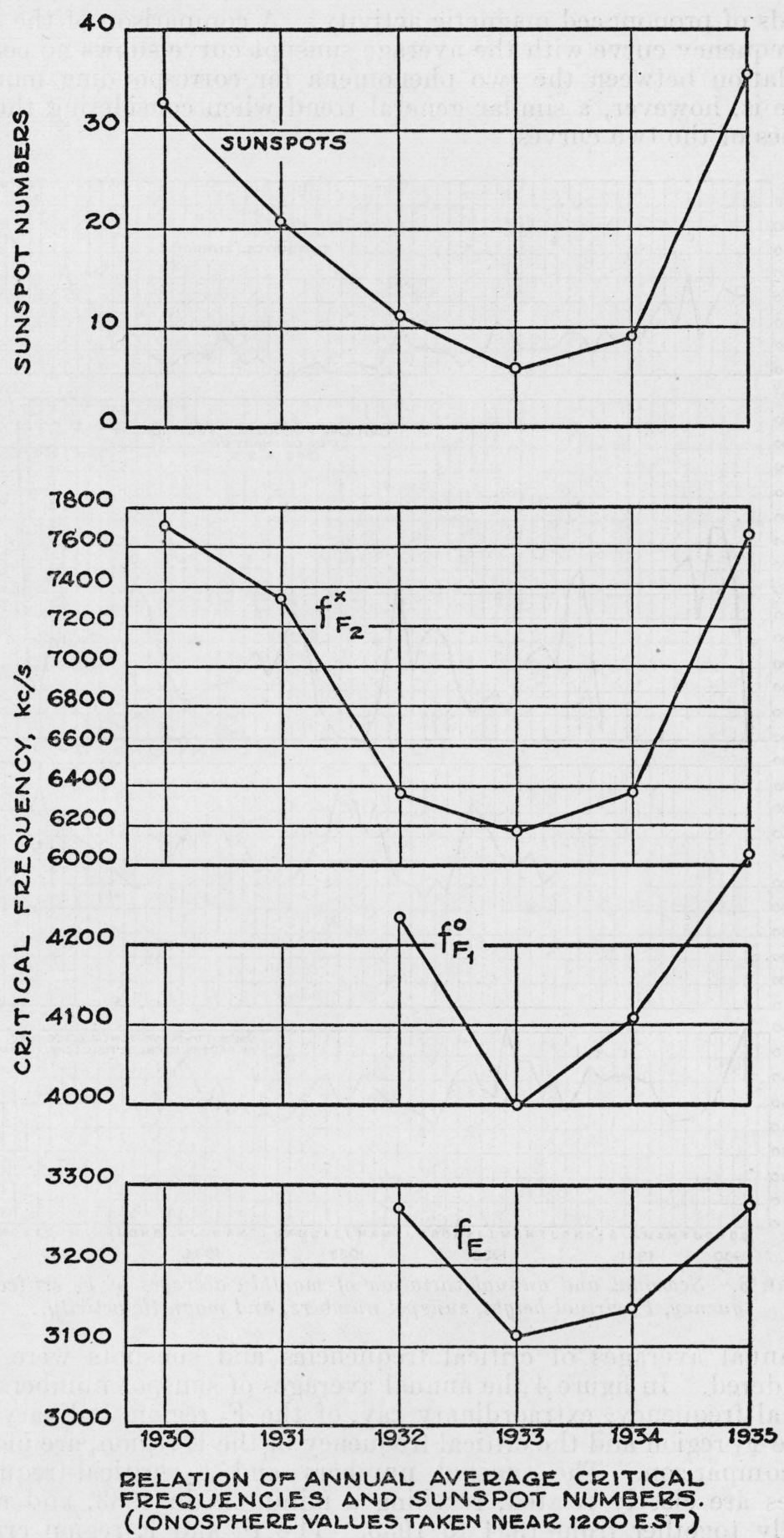

FIGURE 4.-Annual averages of critical frequencies for the three ionosphere regions compared with the annual average of sunspot numbers. 
nounced (the ordinates in the figure for $F_{1}$ and $\mathrm{E}$ are different in scale from those of the $\mathrm{F}_{2}$ ).

The correlation of these annual averages is suggestive of the possibility of forecasting the most suitable radio frequencies which might be utilized for communication purposes during certain periods of the sunspot cycle. The maximum frequency which would return to earth would be approximately the value of the critical frequency at normal incidence multiplied by the secant of the angle of incidence. ${ }^{7}$ For the $\mathrm{F}_{2}$ region the maximum value of the secant would be between 3 and 4, depending upon the height of the region above ground.

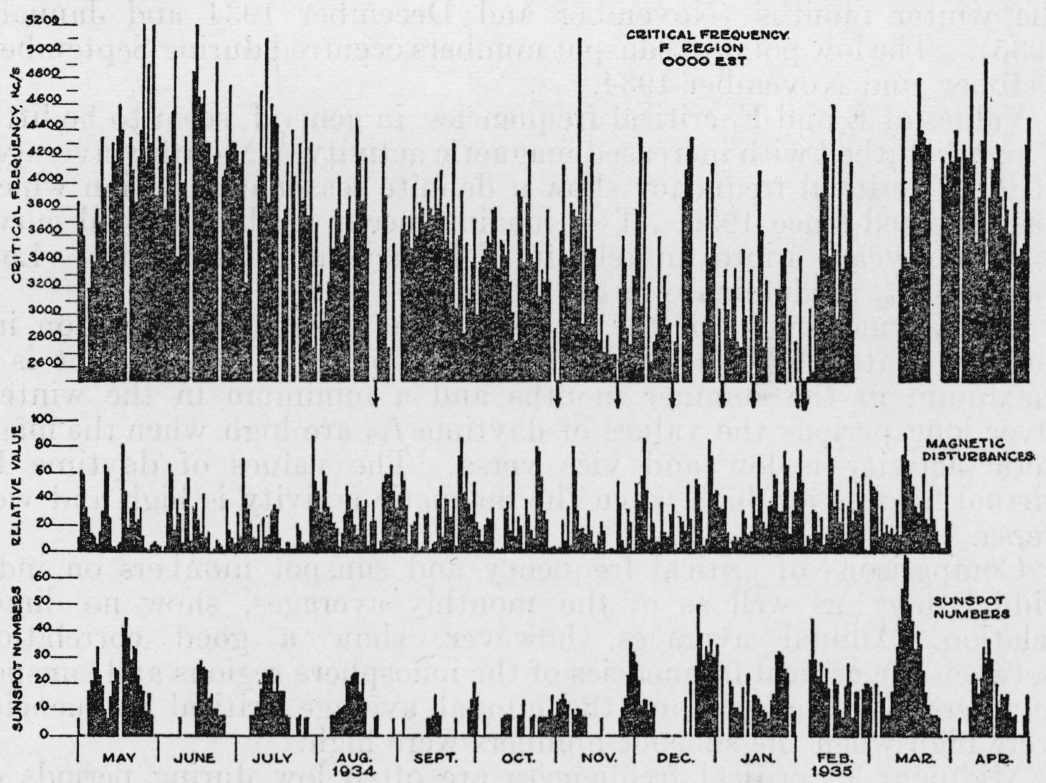

FiguRe 5.-Comparison of midnight $F^{2}$ critical frequency with magnetic disturbances and sunspot numbers.

Records of midnight $\mathrm{F}$ region critical frequencies are obtained nightly from a multifrequency automatic recorder developed by Gilliland. ${ }^{8}$ In figure 5. these night values are plotted in block form for 1 year, May 1934 to April 1935, inclusive. For purposes of comparison the magnetic activity and sunspot numbers are plotted in a similar form and placed in a corresponding position under the ionosphere diagram. The magnetic disturbances are taken from the DeBilt magnetic character figures for 44 different locations through the world. The value for an individual day on the curve in figure 5 represents the sum of the DeBilt character figures. The sunspot numbers are the provisional numbers (Zurich) for each day. The $\mathrm{F}$ critical frequency shown is for the extraordinary ray. Blank spaces extending to the bottom of the block show that the record was either spoiled or missing. The arrows pointing downward from the bottom of the block show that the critical frequency was below $2,500 \mathrm{kc} / \mathrm{s}$. $(2,500 \mathrm{kc} / \mathrm{s}$ is the lower limit of frequency of the automatic recorder).

7 See footnote 3 .

$8 \mathrm{~T}$. R. Gilliland, Note on multi-frequency automatic recorder of ionosphere heights. BS J. Research 11, 561-566 (1933) R P608; Proc. Inst. Radio Engrs. 22, 236-246 (1934). 
Comparison of the critical-frequency diagram with that for magnetic disturbances shows that in quite a number of instances a drop in the critical frequency happens on a night when there is increased magnetic activity. Best agreement appears in the summer months.

The highest groups of critical frequencies appear to be associated with minimum groups of magnetic activity.

Sunspot numbers show very little correlation with the criticalfrequency curve.

The seasonal variation for midnight critical frequencies for this particular year shows the values high in the summer and lower in the winter months (November and December 1934 and January 1935). The low point in sunspot numbers occurred during September, October, and November 1934.

Values of $\mathrm{E}$ and $\mathrm{F}_{1}$ critical frequencies, in general, seem to be little if any disturbed with increased magnetic activity. Monthly averages of the $\mathrm{F}_{2}$ critical frequency show a definite seasonal variation which has repeated since 1930. Two maxima occur in the seasonal curve for each year, approximately in February and November. Low values of $f_{\mathrm{F} 2}^{x}$ predominate in the summer.

The virtual height of the $\mathrm{F}_{2}$ region has a seasonal variation inversely related to that of the critical frequency. The height is a maximum in the summer months and a minimum in the winter. Over long periods the values of daytime $f_{\mathrm{F} 2}$ are high when the magnetic activity is low and vice versa. The values of daytime $\mathrm{F}_{2}$ virtual heights are high when the magnetic activity is high and vice versa.

Comparisons of critical frequency and sunspot numbers on individual days, as well as of the monthly averages, show no direct relation. Annual averages, however, show a good correlation between the critical frequencies of the ionosphere regions and sunspot numbers. For all regions the annual average critical frequencies were high when the sunspot numbers were high.

Midnight $\mathrm{F}_{2}$ critical frequencies are often low during periods of high magnetic activity, especially in the summer months; this condition was not found during the winter.

WASHington, July 18, 1936. 